\title{
Gestão indireta na atenção hospitalar: análise da contratualização por publicização para rede própria do SUS
}

\author{
Indirect management in hospital care: analysis of contractualisation \\ by outsourcing of SUS hospitals
}

Thadeu Borges Souza Santos ${ }^{\mathbf{1}}$ Jessica Santos de Souza ${ }^{\mathbf{2}}$, Juliete Sales Martins ${ }^{\mathbf{3}}$ Lilian Barbosa Rosado ${ }^{4}$, Isabela Cardoso de Matos Pinto ${ }^{5}$

1 Universidade do Estado da Bahia (Uneb) - Salvador (BA), Brasil. Orcid: https://orcid. org/0000-0003-24973889

thadeu100@gmail.com

2 Universidade Federal da Bahia (UFBA) - Salvador (BA), Brasil.

Orcid: https://orcid. org/0000-0003-38340775

jessicaenf@yahoo.com.br

3 Universidade Federal da Bahia (UFBA) - Salvador (BA), Brasil.

Orcid: https://orcid. org/0000-0002-83960837

ju.lysa.martins@hotmail.com

4 Universidade Federal da Bahia (UFBA) - Salvador (BA), Brasil.

Orcid: https://orcid org/0000-0001-86619338

lilian_rosado@hotmail.com

5 Universidade Federal da Bahia (UFBA) - Salvador (BA), Brasil.

Orcid: https://orcid.

org/0000-0002-1636-

2909

isabelacmp@gmail.com
DOI: $10.1590 / 0103-11042018 S 217$

RESUMO Objetivou-se analisar contratualização e prestação de contas adotados na publicização de serviços hospitalares no Sistema Único de Saúde (SUS) Bahia. Pesquisa qualitativa, sendo fontes contratos, relatórios trimestrais de gestão, entrevistas com atores da alta direção da atenção hospitalar no estado e características hospitalares segundo Cadastro Nacional de Estabelecimentos de Saúde. Conceitualmente, adotou-se prestação de contas e desempenho articulados à fase de implementação do Ciclo da Política Pública. A expansão das Organizações Sociais, que apresentou orçamento composto por parte fixa e variável que é condicionada ao desempenho, seus indicadores gerenciais e assistenciais, que são preestabelecidos, e o plano de metas justificam ocorrência de cortes e/ou reequilíbrios orçamentários. Todavia, quanto à cobertura assistencial, a baixa correlação entre metas contratuais e necessidades de saúde do território foi marcante. Os aditivos contratuais foram essenciais para ampliação dos leitos, porém não corresponderam à necessidade de mais recursos humanos e determinaram importante desafio para capacidade de reequilíbrios orçamentários. Ademais, sobre a metodologia de monitoramento e controle da tecnoestrutura, percebeu-se notória fragilidade, dada a insuficiência de indicadores e incipiente análise crítica do desempenho hospitalar apresentado nos relatórios. Considera-se que o modelo, que tem base doutrinária na perspectiva neogerencialista, foi implementado sem simultânea melhoria do monitoramento, nó górdio do poder contratante estatal.

PALAVRAS-CHAVE Políticas públicas de saúde. Descentralização. Regulação e fiscalização em saúde. Hospitais públicos.

ABSTRACT The purpose of this study was to analyze contracting and rendering of accounts adopted in the publicity of hospital services in the Unified Health System (SUS) Bahia. Qualitative research, based on contracts, quarterly management reports, interviews with senior management of hospital care in the state, and hospital characteristics according to the National Register of Health Establishments. Conceptually, accountability and performance were adopted, with implementation of the Cycle of Public Policy. The Social Organizations presented a budget consisting of fixed and variable parts that is conditioned to performance, its management and 
assistance indicators are pre-established and the goals plan justifies the occurrence of budget cuts and/or rebalancing. The low correlation between contractual goals and health needs of the territory was striking. The contractual additives were essential for expansion of hospital beds, but did not meet the need for more human resources and determined an important challenge for the capacity of budgetary rebalancing. Moreover on the methodology of monitoring and control of the technostructure, a remarkable fragility was observed, given the insufficiency of indicators and the incipient critical analysis of the hospital performance presented in the reports. It is considered that the model, which has a doctrinaire basis in the neo-managerial perspective, was implemented without simultaneous improvement of the monitoring, Gordian knot of the contracting power of the state.

KEYWORDS Public health policy. Decentralization. Health care coordination and monitoring. Hospitals public.

\section{Introdução}

A relação entre o público e o privado no setor saúde é anterior à criação do Sistema Único de Saúde (SUS). Sua historicidade remete às ordens religiosas no período colonial, perpassa o processo de contratação de serviços privados pelos Institutos de Aposentadorias e Pensões da Era Vargas ${ }^{1}$ e encontra espaço na Constituição Federal do Brasil de 1988, abrindo a possibilidade de contratualização do privado em caráter complementar no SUS².

$\mathrm{Na}$ administração pública, foram introduzidas diferentes personalidades jurídicas de administração indireta, a exemplo das autarquias, fundações e empresas públicas que demonstraram certo esgotamento em função da rigidez, especialmente quanto às gestões orçamentária, de pessoas e de compras ${ }^{3}$. Em vista disso, buscou-se novas alternativas. Foi com o Plano Diretor da Reforma Administrativa do Estado (PDRAE) que se criou o Programa Nacional de Publicização, reestabelecendo a descentralização da responsabilidade de gestão do ente público estatal para o 'público não-estatal'; entre os serviços, encontram-se os hospitais públicos ${ }^{4}$. Como alternativas, foram criadas novas naturezas jurídicas, denominadas como Modelos Alternativos de Gestão Indireta (Magi), tais como Organizações Sociais (OS) e Organização da Sociedade Civil de Interesse Público (Oscip) nos anos $1990^{3}$ e Parceria Público-Privada (PPP), Empresa Brasileira de Serviços Hospitalares (EBSERH) e Organizações da Sociedade Civil (OSC) na década 2000 5-7.

Para formalização das relações entre público e privado, o PDRAE estabelecia o 'contrato de gestão'4, documento entendido como instrumento celebrado entre o poder público e entidades da administração direta, indireta e entidades privadas qualificadas como OS, fixando metas de desempenho e indicadores de acompanhamento ${ }^{8}$. Em relação aos diferentes modelos adotados, podem ser citados também os contratos de concessão para PPP, o termo de cooperação e execução descentralizada para EBSERH e os termos de colaboração, fomento ou acordo de cooperação que são destinados às OSC.

Mantendo a finalidade contratual, ainda podem ser citados o Termo de Compromisso entre Entes Públicos (TCEP), decorrente das 
Normas Operacionais Básicas de Atenção à Saúde e reiterado pelo Pacto de Gestão9-11, e o Contrato Organizativo da Ação Pública da Saúde (Coaps), que foi estabelecido no Decreto $\mathrm{n}^{0} 7.508 / 11^{12}$.

Tendo em vista a implementação das Redes de Atenção à Saúde (RAS), o Ministério da Saúde adotou contratualização para aporte orçamentário complementar ao teto da Média e Alta Complexidade (MAC) por meio dos Fundo de Ações Estratégicas e Compensação (Faec) e com os acordos aos programas de contratualização dos Hospitais de Ensino, Filantrópicos e de Pequeno Porte.

Essa formalização contratual fomentada na administração pública'13 ficou estabelecida como obrigatória para atenção hospitalar no SUS por intermédio da Política Nacional de Atenção Hospitalar (PNHOSP) ${ }^{\mathbf{1 4}}$. Cabe destacar três diretrizes dessa política: a regulação das ações e serviços por parte do ente contratante; descrição de responsabilidades por parte dos hospitais quanto a assistência, ensino-pesquisa, gestão e avaliação; e o monitoramento, avaliação e auditorias sobre as metas e serviços ${ }^{6}$.

Assim, pode-se considerar existência de bases legitimadoras da denominada gestão pública contratualizada, em que ocorre tentativa de passagem das concepções de Estadoliberal ou Estado-social à perspectiva de Estado-regulador, principalmente pelo distanciamento feito à administração burocrática e concomitante aproximação à gerencial15,16.

$\mathrm{Na}$ saúde, a necessidade da regulação foi reiterada com a Política Nacional de Regulação no SUS, que deve ser sistêmica e voltada para atenção à saúde e ao acesso assistencial17. Quanto à regulação sistêmica, determina-se responsabilidade em definir normas, monitorar e fiscalizar resultados, controlar e avaliar prestação de cuidados ${ }^{18}$.

No caso da atenção hospitalar no SUS Bahia, a OS foi o modelo largamente e historicamente adotado para viabilização da expansão da rede própria, além da inovação com o modelo de PPP para um dos cinco novos hospitais públicos, a partir de 2007.
Essa condição permite afirmar que a rede própria hospitalar do SUS Bahia se caracteriza pela multiplicidade de naturezas administrativas e, consequentemente, com fomento à gestão pública contratualizada, pois adota TCEP, contrato de gestão e contrato de concessão. Com enfoque no processo de publicização adotado como via de descentralização da gestão, dá-se ênfase ao modelo de OS, fenômeno que não foi identificado na revisão de literatura nacional e internacional, permitindo afirmar que é uma lacuna científica quanto aos estudos sobre instrumentos de contratualização e regulação da gestão da atenção hospitalar no SUS.

Entendendo que é por meio do contrato de gestão que a OS celebra compromissos e se submete à fiscalização do Poder Público ${ }^{19}$, teve-se como objetivo deste estudo analisar instrumentos de contratualização e prestação de contas adotados na publicização de serviços hospitalares no SUS Bahia entre 2007 e 2014.

\section{Material e métodos}

Trata-se de estudo qualitativo, com foco na análise documental e empírica ${ }^{20}$, cujo lócus foi a Secretaria Estadual de Saúde da Bahia (Sesab). Vincula-se ao Observatório de Análise de Políticas em Saúde (OAPS), é parte da pesquisa 'Modelos alternativos de gestão na atenção hospitalar do SUS' que foi aprovada pelo Comitê de Ética na Pesquisa sob parecer CAAE no 41872715.2.0000.5030. As fontes de dados foram entrevistas realizadas com gestores do nível central da Sesab; e como documentos, adotou-se Contratos de Gestão e os Relatórios Trimestrais de Gestão (RTG), que são instrumentos de gestão firmados entre a Sesab e as OS para legitimar a publicização das unidades hospitalares da rede própria e instrumento de controle, apresentado pela Sesab ao Conselho Gestor das Organizações Sociais da Secretaria de Administração do Estado (Congeos/Saeb) 
com finalidade de controle e acompanhamento da publicização respectivamente.

Foram incluídos para análise os contratos firmados e relatórios de 2007 a 2014, que corresponde ao período de governo estadual que planejou e implementou expansão da atenção hospitalar no SUS Bahia, tendo a notória capacidade de abertura de cinco novas unidades e ampliação da adoção dos Magi para rede própria ${ }^{\mathbf{2 1} 22}$. Foram, ao total, incluídos 259 documentos, sendo: 16 Contratos de Gestão e 243 RTG. Como critérios de inclusão, as unidades hospitalares deveriam ser da rede própria do SUS Bahia, corresponderem ao período de 2007 a 2014 (dois períodos completos de governo estadual), terem sido aprovados pelo Congeos/Saeb e que os contratos fossem de publicização por OS.

Todos os documentos foram submetidos ao plano de análise que consistia em: leitura profunda e exaustiva ${ }^{20}$, reconhecimento dos aspectos caracterizadores dos instrumentos de gestão e prestação de contas, tabulação em planilha Microsoft Excel $^{\circledR}$, agrupamento de fatores de análise e sínteses de elementos crítico-científicos. Posteriormente, fez-se alinhamento com marcos normativos e com os dados caracterizadores das unidades hospitalares conforme Cadastro Nacional de Estabelecimentos de Saúde (CNES).

Para potencializar a validação interna do estudo, foram extraídas unidades de conteúdo de entrevistas ${ }^{20}$ realizadas com 13 gestores situados na gestão central da Sesab e diretamente relacionados com o fenômeno de estudo, pois assumiram funções estratégicas na equipe dirigente da Secretaria.

A estruturação em quadros analíticos possibilitou identificar características dos instrumentos contratuais quanto aos aspectos privilegiados pelos documentos, tais como: descrição epidemiológica da região adstrita e aspectos orçamentário-financeiros, técnico-administrativos, responsabilidades assistenciais e contratuais mínimas.

Como referencial teórico-analítico, articularam-se os elementos da Prestação de
Contas e Desempenho (PCD) do Triangulo de Ferro de Matus (TFM) ${ }^{23}$ com o Ciclo da Política Pública (CPP) ${ }^{\mathbf{2 4}, 25}$. Assim, focalizou-se o sistema de monitoramento e avaliação periódico, preocupação com o desempenho e cumprimento do plano contratualizado ${ }^{23}$. Enquadramento que permitiu criticidade sobre a centralidade regulatória estatal quanto à capacidade de gestão por meio da publicização na atenção hospitalar do SUS Bahia.

Dessa forma, apresentam-se os resultados a partir dos dois quadros e com contrapontos feitos pelos participantes sobre o sistema de monitoramento e controle da contratação de OS para gestão hospitalar no SUS Bahia. As sínteses subsidiaram análise e compreensão quanto à $\mathrm{PCD}$, vértice do TFM²3.

\section{Resultados e discussões}

As análises documentais, dados do CNES e entrevistas permitiram estruturação dos resultados e respectivas discussões em relação a quatro aspectos: a caracterização dos contratos de gestão, a caracterização dos relatórios de prestação de contas ao Programa Estadual de Organizações Sociais (Peos), a compreensão orçamentária das contratualizações e as fragilidades dos instrumentos na percepção dos gestores da atenção hospitalar.

\section{Quanto aos instrumentos de contra- tualização de gestão hospitalar}

A leitura em profundidade dos 16 contratos de gestão permitiu extrair 5 elementos centrais: descrição do perfil de atenção à região territorial, dimensões orçamentário-financeiras, dimensões técnico-administrativas, as responsabilidades assistenciais e obrigações contratuais mínimas.

Em relação à descrição socioepidemiológica da região adstrita, esperava-se identificar melhores descrições territoriais e sanitárias. Os contratos apresentaram simplesmente o logradouro, determinação 
de assistência continuada, pública e com respeito aos princípios e legislação do SUS. Citaram também o rol de competências ambulatoriais e de assistência hospitalar que contemplam a vocação das unidades hospitalares. Não houve menção à caracterização social, ambiental e demográfica que constituem as necessidades de saúde da concepção regionalizada. A rasa descrição não contempla as especificidades recomendadas pelo Decreto $\mathrm{n}^{0} 7.508 / 2011^{12}$.

No que tange à dimensão orçamentário-financeira, o contratante se compromete a cumprir o repasse pactuado, global e mensalmente, composto por percentuais valor de repasse fixo e outra parte variável e compondo despesas previstas do Estado e de repasse obrigatório condicionado à prestação de serviços e atenção ao reequilíbrio econômico-financeiro. À contratada, por sua vez, fica garantido o direito de reembolso extra referente à utilização de Órteses Próteses e Materiais Especiais, aditivos para investimentos em infraestrutura e equipamentos, possibilidade de investir recurso em mercado financeiro, gasto máximo de $65 \%$ com Recursos Humanos de Saúde (RHS) e a prestação de contas mensalmente.

Percebe-se que o Estado insere os gastos da publicização em sua programação de orçamento público, tendo como teto o valor contratual, que pode ser uma vantagem competitiva do modelo ${ }^{26}$. Contudo, obriga-se aos novos aportes financeiros adicionais por meio de termo aditivo e utilização de insumos especiais de alto custo, condição que permite escape do controle financeiro baseado na gestão eficiente e eficaz do orçamento público e de gestão baseada em atividades ou desempenho ${ }^{27}$.

No conteúdo técnico-administrativo, o contratante se obriga a eliminar possíveis entraves burocráticos que impeçam a flexibilização desejada pelo modelo com vistas ao alcance de metas contratuais. Comprometese também com o monitoramento periódico por meio de visitas presenciais trimestrais, análise dos Relatórios de Informação Hospitalar (RIH) e prestação de conta ao Congeos/Saeb e Tribunal de Contas do Estado (TCE). A contratada, por sua vez, deve estar legalmente autorizada para parceria, demonstrar capacidade operacional e priorizar qualidade compatível à acreditação hospitalar. Sua gestão precisa adotar processo seletivo, respeitar direitos trabalhistas e princípios da administração pública, monitorar produtividade de internações e cirurgias, satisfação de usuários, notificar produção e prestação de serviços em Sistemas de Informação Ambulatorial e Hospitalar e apoiar sistema de regulação de pacientes.

Especificamente para o sistema de monitoramento e controle, os parceiros contratados devem emitir os RIH mensalmente, apresentando produtividade comparada às metas estabelecidas, dados da gestão eficiente de leitos e anexos como notas fiscais, faturas/taxas/impostos quitadas, licenças/ alvarás atualizados.

Do ponto de vista assistencial, o contratado orienta adoção de protocolos terapêuticos e a continuidade da prestação de serviços. A OS deve apresentar capacidade condizente às Políticas de Saúde, equipe qualificada ao porte e perfil assistencial, atender às emergências por demanda espontânea, respeitar direitos do paciente e princípios da humanização e gestão da clínica ampliada; além de disponibilizar documentações ao contratante e Auditoria do SUS e manter em funcionamento as comissões de serviços hospitalares.

A adoção de critérios qualitativos nos instrumentos de contratualização coaduna com as recomendações ministeriais, que estruturaram posteriormente as diretrizes formuladoras da PNHOSP14. Além disso, sobre as metas mínimas contratualizadas, os 16 contratos apresentam composição orçamentária, sendo $70 \%$ de valor fixo e $30 \%$, variável. Existem nove indicadores quantitativos administrativos que subsidiam o pagamento contratual. Como indicadores, 
tem-se 12 comissões permanentes além das taxas de satisfação do usuário, treinamento de cuidadores, visitação a equipamentos sociais, reunião multiprofissional, discussão de casos clínicos, referência para continuidade de tratamentos e relação número de enfermeiros por leitos.

O acompanhamento pelo Poder Público contratante é obrigatoriedade legal, que condiciona as irregularidades à ação de controle externo ${ }^{28}$. Todavia, esse monitoramento se concretiza por visitações periódicas não contínuas e informações dos próprios contratantes. Situação que impõe ao contratante a conivência com os dados fornecidos e em risco de baixa acurácia avaliativa da real eficiência e efetividade e, consequentemente, com baixa accountability (controle, fiscalização e avaliação pelos atores políticos) fomentada com o modelo gerencialista e/ou controle social sobre as implementações de políticas públicas ${ }^{29}$.

\section{Quanto aos relatórios de prestação de contas ao Peos}

Os RTG evidenciaram sobre a responsabilidade da Secretaria Estadual de Saúde (SES) quanto ao monitoramento de seus entes públicos não estatais parceiros para gestão indireta dos hospitais da rede própria, que pode ser estruturado no quadro 1 .

Diante dos formatos e da periodicidade não tão padronizados inicialmente, eles não continham quadros comparativos com metas por resultados alcançados. Porém, houve incorporação paulatina de alguns elementos estruturantes, tais como: caracterização do perfil da unidade relatada; quadros com quantitativo de RHS, procedimentos contratualizados e percentuais de cobrança conforme metas alcançadas; taxas de ocupação média, realização de procedimentos de Serviço de Apoio Diagnóstico e Terapêutico (SADT), de cesarianas e mortalidade.

Quadro 1. Aspectos analítico-qualitativo da série histórica dos Relatórios Trimestrais de Gestão da rede hospitalar própria publicizada do SUS Bahia, entre 2007 e 2014

\begin{tabular}{|c|c|}
\hline Ano & Aspectos regulatórios registrados \\
\hline 2007 & $\begin{array}{l}\text { Os relatórios das seis unidades hospitalares consideraram comuns a redução de repasses justificados pelos cortes orçamentários associados } \\
\text { ao não cumprimento de metas contratuais e a existência de justificativas bem fundamentadas para o não cumprimento de metas contratuais, } \\
\text { citando cláusulas contratuais não respeitadas. }\end{array}$ \\
\hline 2008 & $\begin{array}{l}\text { Quatro dos sete relatórios hospitalares apresentaram: avaliações de janeiro a dezembro; quadro de pessoal com informações relatadas; mu- } \\
\text { dança do modelo de gestão terceirizada para publicizada; repactuações que possibilitaram os hospitais ao cumprimento de metas contratua- } \\
\text { lizadas; imagens na descrição do perfil das unidades hospitalares. }\end{array}$ \\
\hline 2009 & $\begin{array}{l}\text { Cinco das dez unidades criticaram existência de unidade com apresentação de apenas dois relatórios (semestrais); ocorreu de uma unidade } \\
\text { apresentar quadro com quantitativo de pessoal e respectiva carga horaria; houve unidade em que os relatórios não constaram metas a serem } \\
\text { cumpridas, apenas a quantidade contratada em valor absoluto; houve aplicação de penalização contratual por não cumprimento de meta } \\
\text { estabelecida; inclusão de anexo com quadro de percentuais a serem pagos a depender da meta alcançada. }\end{array}$ \\
\hline 2010 & $\begin{array}{l}\text { Seis dos onze hospitais consideraram: metas como taxa de ocupação e média de permanência foram ajustadas no decorrer do ano; houve } \\
\text { diminuição na quantidade de leitos para } 129 \text { em uma unidade hospitalar; ocorreu de seis unidades apresentarem quadro com quantitativo de } \\
\text { pessoal e respectiva carga horaria nos quatro relatórios do ano; apresentou-se o cumprimento de procedimentos de SADT muito acima do } \\
\text { contratualizado em um relatório, porém sem justificativa ou readequação contratual. }\end{array}$ \\
\hline 2011 & $\begin{array}{l}\text { Cinco de onze unidades criticaram não haver clareza na descrição ou completude nas conclusões e não estabelecimento de metas contra- } \\
\text { tuais claramente, prejudicando avaliar se houve realmente o cumprimento contratual; houve crescimento do quantitativo de leitos para } 119 \\
\text { e } 202 \text { em duas unidades; considerou-se como alcançada a meta ambulatorial, embora tenha atingido apenas } 33 \% \text {; conclusão apresenta } \\
\text { alcance de metas apesar de percentuais baixos de produção de serviços ambulatoriais; houve repetição do valor de alguns indicadores em } \\
\text { relatórios consecutivos; houve aplicação de desconto orçamentário de } 6 \% \text { no valor contratual pelo não alcance da meta contratual estabele- } \\
\text { cida para produção ambulatorial; passou-se a se avaliar a taxa de cesárea como indicador contratual; foi incluída a taxa de mortalidade geral } \\
\text { como indicador. }\end{array}$ \\
\hline
\end{tabular}


Quadro 1. (cont.)

2012 Cinco relatórios de doze hospitais apontaram: alcance de todas as metas contratuais, porém existiu quadro de informações em um dos relatórios que não apresenta alcance de meta de internação; crescimento do quantitativo de leitos; inexistência de padronização de modo a prejudicar uniformidade da análise de avaliação quanto ao alcance das metas. Houve um caso importante: no 10 trimestre o valor alcançado para Média de Permanência foi de 6,16, quando a meta era 6,0. Nesse item a meta foi dada como alcançada. Porém, no 2 ํ trimestre o valor alcançado foi 6,13 e a mesma foi tida como não alcançada. Não é explicitado o não alcance de meta no relatório, somente sendo percebido o não cumprimento quando analisado quadro e justificativa. E não cumprimento de meta da taxa de cesárea contratualizada.

2013 Nove de quinze unidades analisadas destacaram: aumento no número de leitos totais, porém com manutenção do quantitativo anterior quando somado o quantitativo de leitos especificados, evidenciando inconsistência do número de leitos informados; aumento na taxa de ocupação hospitalar; aumento do número total de leitos para 110, 244, 280, 97 em quatro unidades analisadas, sem especificar consistência do referido aumento; continuidade e aumento do não cumprimento de metas contratuais; relatórios com semelhanças, mudando apenas as informações sobre os quantitativos de procedimentos; permanência de justificativas semelhantes sem permanência do não cumprimento de metas; não há clareza na descrição ou completude nas conclusões dos relatórios; aumento no quantitativo do número de leitos erradamente provocou notificação da unidade hospitalar; não cumprimento paulatino das metas contratuais e/ou taxas de ocupação durante todo o anos, com as mesmas justificativas. Houve solicitação de ratificação de percentual da taxa de ocupação pelo gestor central da saúde, em decorrência do erro contido no relatório que apresentava percentual abaixo do contratualizado.

2014 Sete das dezesseis unidades hospitalares analisadas tiveram críticas quanto ao: não cumprimento de metas pactuadas para as taxas de internação, infecção hospitalar, cesárias, ocupação hospitalar, permanência média e mortalidade, bem como das metas ambulatoriais, muitas vezes sem justificativas; não existia clareza na descrição ou completude nas conclusões de relatórios; casos em que a produtividade realizada ultrapassava a quantidade contratualizada exageradamente; ocorrência de apresentação quantitativa de produtividade ambulatorial, SADT e internação em quadros desuniformes. Um caso de mudança de ente contratualizado ocorreu, evidenciando apresentação simultânea de dois relatórios distintos para gestão do mesmo hospital.

Fonte: Elaboração própria, com base nos Relatórios Trimestrais de Gestão de 2007 a 2014.

Estes instrumentos celebram acordos com responsabilidades e obrigações a serem cumpridas pelas partes e formas de controle sobre o desempenho da prestação de serviço que fundamentam a atividade de regulação' ${ }^{19}$. Todavia, a baixa especificidade dos dados de monitoramento da contraprestação parece contrariar a ideia de que a gestão indireta superaria a menor eficiência operacional existente na administração pública ${ }^{30}$. Ademais, a instrumentalização do seu processo de monitoramento somente se efetivou como manual técnico-educativo no estado da Bahia em 201631.

Quanto aos aspectos incorporados aos RTG, seis chamaram atenção quanto à fragilidade regulatório-contratual na construção histórica da análise crítica feita a partir da leitura dos RTG. A primeira trata da não padronização do formato dos relatórios que dificultava a análise comparativa e proporcional dos resultados apresentados. As demais tratam da descontinuidade dos cortes orçamentários consequentes ao não cumprimento de metas estabelecidas, inclusão de novos indicadores sem estimar valores limites; realização de procedimentos de SADT superior ao pactuado contratualmente; repactuação como fomento ao cumprimento de metas contratuais e por aumento de leitos. Outrossim, apesar de acordos de responsabilidades e obrigações, a fragilidade das atividades de regulação e monitoramento contrariam a eficiência operativa que a gestão indireta superaria.

\section{Quanto ao aspecto orçamentário das contratualizações}

A princípio, tem-se a análise sobre o ponto de vista orçamentário que os RTG permitiram desenvolver e sintetizar no quadro 2. O maior quantitativo de relatórios (112) correspondeu a cinco hospitais que se mantiveram publicizados de 2007 a 2014, apesentando fidelização das parcerias aos 
objetos contratuais; e o crescimento de 5 para 16 hospitais com gestão por OS aponta progressiva ampliação anual da publicização. Fenômeno anteriormente descrito como experiências emergentes no início dos anos $2000^{32}$ evoluiu a ponto de ser visto como perspectiva consolidada de gestão pública nessa década, tendo em vista as análises dos casos paulista, goiano e baiano ${ }^{26,33}$.

Sobre a distribuição territorial, as unidades hospitalares geridas por OS estão em sete das nove macrorregiões de saúde desde 2007. Essas macrorregiões são leste (principalmente), nordeste, oeste e extremo sul. Característica que suscita necessidade de melhoria do sistema regulador, nova função assumida pelo Poder Público contratante, que deve controlar, avaliar e auditar com vistas à melhoria da equidade do acesso e garantia assistencial efetiva ${ }^{18}$.

Quadro 2. Aspectos analítico-orçamentários da gestão pública contratualizada adotada para rede hospitalar própria publicizada do SUS Bahia, entre 2007 e 2014

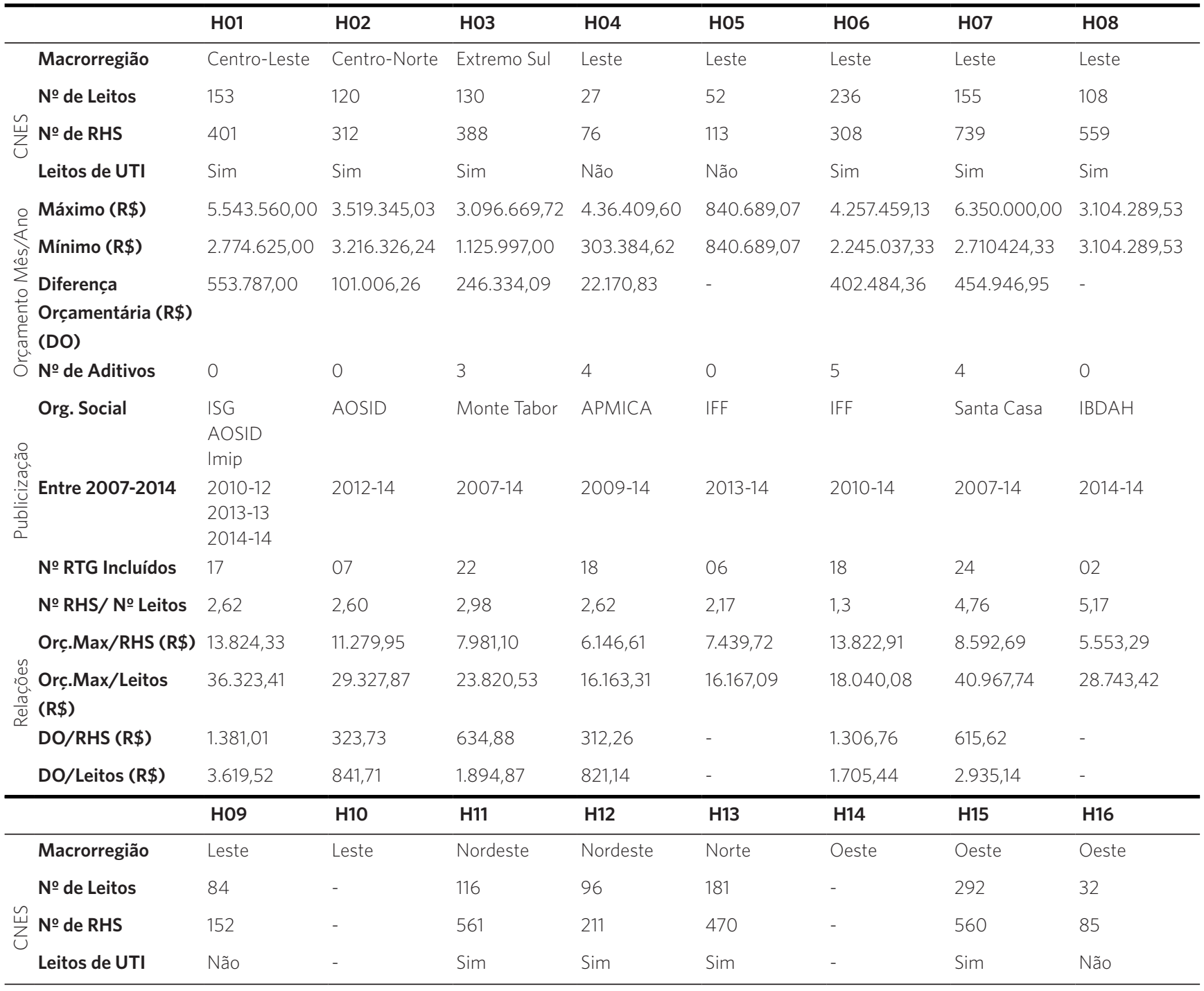




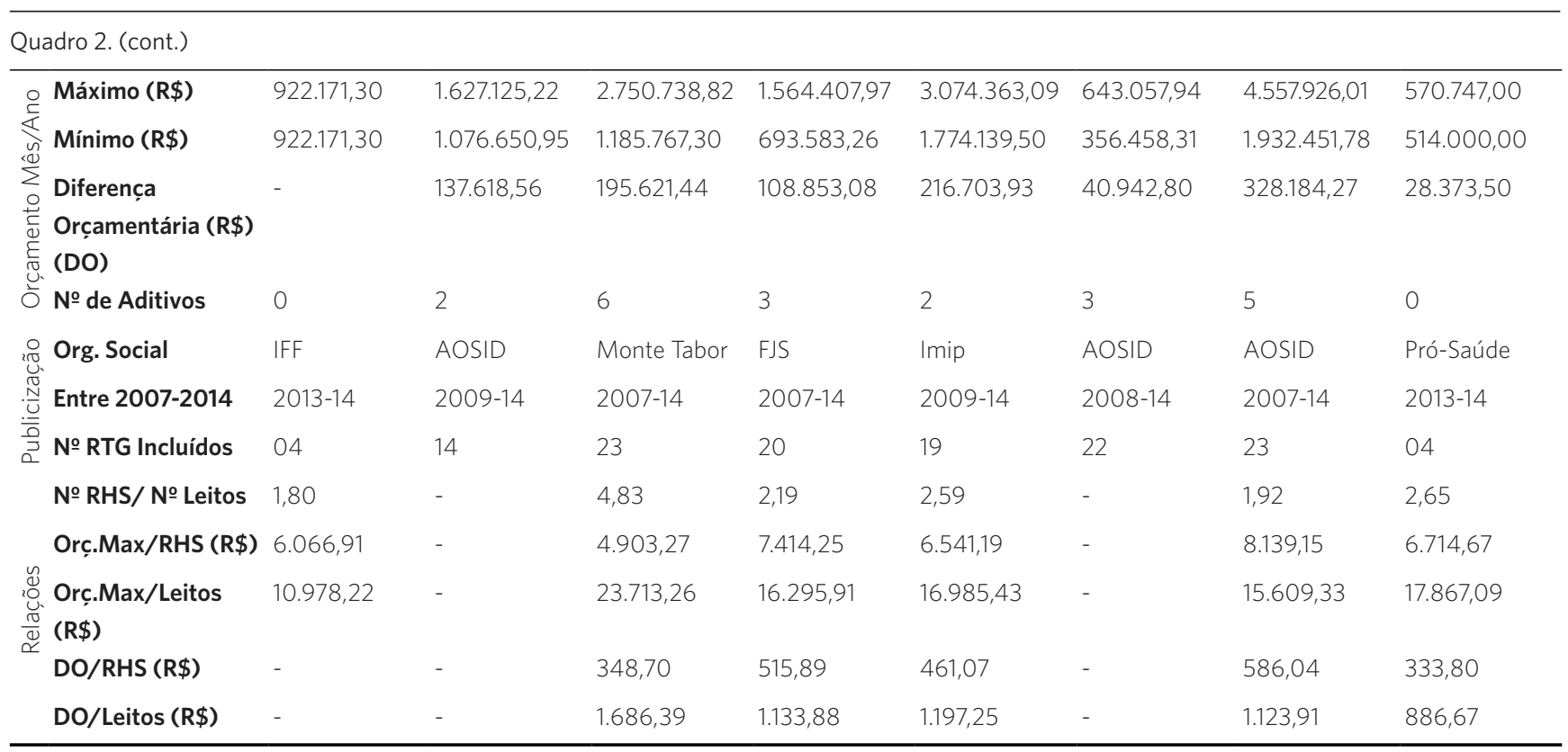

Fonte: Elaboração própria, com base nos Relatórios Trimestrais de Gestão de 2007 a 2014.

Quanto às OS, 10 se responsabilizaram pela gestão de 16 hospitais da rede própria. Entre elas, destacaram-se as Obras Sociais Irmã Dulce (Osid) à frente de cinco estabelecimentos, Instituto Fernando Filgueiras (IFF) com três, Monte Tabor Centro Ítalo Brasileiro de Promoção Sanitária (Monte Tabor) e Fundação Professor Martiniano Hospitalar Imip Hospitalar ou Instituto de Medicina Infantil Fernando Figueira (Imip) com duas cada. Quanto à permanência da gestão por período ininterrupto, cinco unidades permaneceram por todo o período de 2007 a 2014 com a mesma OS, e apenas um hospital teve relatórios de mais de uma OS responsável. Situação que leva a supor que a publicização foi estratégia de longo prazo para os serviços hospitalares, e ainda uma clara fidelização entre os contratante e contratados.

A partir da diferença entre os valores máximo e mínimo dos orçamentos apresentados nos relatórios, a partir da série histórica, pode-se inferir análises sobre quantitativo de leitos e de RHS. O acréscimo orçamentário no valor mensal/ano ocorreu em todas as 16 unidades hospitalares, porém, não houve fidedignidade na menção dos aditivos de contratos nos relatórios, reiterando a fragilidade do instrumento regulatório e obrigando os pesquisadores à maior atenção quanto às mudanças nos valores citados e, estrategicamente, adoção de série histórica com valores máximos e mínimos por ano correspondente.

Por meio de série histórica, reconheceu-se que os acréscimos orçamentários mês/ ano variaram, sendo proporcionais ao porte hospitalar. As unidades com maior quantitativo de leitos, com maior complexidade por possuírem Unidade de Terapia Intensiva (UTI) e serem de médio e grande porte receberam maior acréscimo orçamentário-contratual no período. Coadunando com a estratégia de implementação das RAS conforme na Portaria n ${ }^{0} 2.395 / 2011^{34}$. A estratégia contratual para expansão da maior complexidade assistencial favorece a SES na ampliação da captação de financiamento da MAC, por intermédio do bloco de incentivos estabelecidos pelo Faec e que estão 
relacionados com a expansão das linhas de cuidados estratégicas ${ }^{34}$.

Quando correlacionado o quantitativo total de RHS com o porte hospitalar e acréscimo orçamentário mês/ano, evidencia-se que as unidades com menores acréscimos se caracterizaram como sendo de pequeno e médio porte com UTI. As unidades com moderado acréscimo-contratual são quatro hospitais de médio e um de grande porte, ambos com leitos de UTI. Como desfecho, as unidades de pequeno porte tiveram menor acréscimo orçamentário-contratual, enquanto as unidades de médio e grande porte tiveram heterogêneo acréscimo correlacionado aos RHS, sendo mais evidente quando correlacionado à existência de leitos de UTI.

O modelo de gestão por OS tem melhor autonomia para contratação de pessoal, sendo este um fator determinante à eficiência do contrato de gestão ${ }^{33}$, além de ser sabido que o plano de incentivos profissionais é pilar da gestão baseada em resultados ${ }^{35}$.

\section{Fragilidades dos instrumentos de gestão e prestação de contas na percepção dos gestores da atenção hospitalar}

Em relação às características relacionadas com os contratos, relatórios de gestão e aspectos orçamentários das contratualizações na gestão indireta por OS, na perspectiva dos atores envolvidos nesse processo, merecem destaque aspectos que foram reconhecidos como fragilidades, quais sejam: prender-se às informações fornecidas pelos contratados, deficiente capacidade instalada para monitoramento, necessidade de aperfeiçoamento dos critérios de acompanhamento, necessidade de incorporação da satisfação do usuário como critério qualitativo e acompanhamento com certo distanciamento em relação aos serviços, como expressados pelos gestores centrais:

A análise desses relatórios às vezes passam até por um crivo de pessoas que não conhecem o segmento da saúde, que não tem essa capacidade toda de questionamento do porquê que não ter cumprido. (GCO3) [e que] A gestão indireta não tem nenhum sistema, são relatórios em Excel, são cálculos que mensalmente os hospitais têm que encaminhar como informações. (GC08).

Há discussão para tentar modificar os indicadores, incorporando outros mais novos, porque as vezes a gente pensa que está moderno, e não está. [...] A gente quer colocar uma pesquisa de satisfação para saber opinião do cliente, pra que ele faça parte desse projeto nosso como um indicador de qualidade. (GCO4).

Nós já identificamos falhas. Essas metas quantitativas são analisadas e avaliadas pela autodeclararão da empresa. E as qualitativas elas são compulsoriamente informadas. Alguns indicadores de qualidade não conseguem acompanhar para poder fazer pagamento [...] são tão simplórios que não conseguem acompanhar o desempenho. Precisa fazer pesquisa de satisfação do usuário. (GC06).

Quanto à capacidade de monitoramento por parte da Sesab, falta organizar um conjunto de conhecimentos necessários à avaliação da gestão de serviços de saúde (complexidades assistenciais, contábil-econômico, engenharia, jurídico e trabalhistas). O Estado deve assumir sua função regulatória, desenvolver nas suas secretarias melhorias da: capacidade de crítica sobre os resultados apresentados conforme as metas contratuais, insuficiente equipe para controle, relatórios de acompanhamento pouco detalhados, distanciamento da equipe de monitoramento por problemas ou longo período de intervalo entre as visitas.

[...] nós precisamos ter mais um conjunto de conhecimentos. [...] precisa ter gente com competência dentro da Secretaria para verificar se a manutenção dos equipamentos está adequada, adequação dos fluxos de atendimentos, se os protocolos de atendimento estão adequados, de 
seleção de pessoas [...] Não é necessariamente que essa competência seja requerida apenas para dois ou três membros da comissão, e sim a Secretaria inteira. [...] teria que ter também melhoria de habilidades na parte administrativa, economia e jurídico, [...] a segurança trabalhista. São essas habilidades que, em tese, o próprio Estado precisa desenvolver na condução do seu processo. (GCO3).

Inclusive vem se promovendo discussões, buscando a revisão da legislação, melhorando e aprimorando. [...] mas o Estado tem crescido muito essa gestão por Organização Social. Mas precisa ir aprimorando porque é muito recurso, precisa que o Estado tenha a capacidade de gastar meIhor, certo. (GCO3).

Eu percebi fragilidade dos controles dos contratos da gestão indireta. [...] As metas qualitativas muitas vezes são simples. Não são metas que apuram com profundidade. $E$ até as quantitativas, pouco acompanhadas pela gestão, em termo do rigor de acompanhamento. [...]sempre fiquei preocupada com aquelas planilhas, dizia: mas como? O que eles apresentam não tem uma crítica mais detalhada. [...] Então eu percebi uma fragilidade na equipe, em termos até de quantidade de pessoas que trabalham na equipe, [...] eu percebia uma fragilidade deste acompanhamento, e dos instrumentos que eles utilizam pra acompanhar que eu não percebia bom nível de detalhamento do valor financeiro por internações e procedimentos. [...] Deveriam estar mais perto da unidade da gestão indireta, acompanhando o dia a dia dela. Eu não conseguia, nas minhas conversas com eles, perceber que havia um acompanhamento mais próximo. (GC05).

Ademais, como aspecto relativos à função regulatória, os fatores correlacionados ao não cumprimento das pactuações contratuais estiveram relacionados com: inexistência de instrumento de avaliação do custo-efetividade sobre os modelos de gestão pública, instrumentos de controle pouco efetivos, monitoramento complexificado pela heterogeneidade das unidades hospitalares, por ser distanciado e pouco crítico, baixa implementação dos conselhos gestores com fomento ao controle social voltado às metas contratuais, não adesão da Sesab aos padrões de instrumentos de contratos e relatórios conforme sistematização do Congeos e processo de monitoramento fragmentado. Condições percebidas nas seguintes falas:

O nível de complexidade que está em um hospital e em outro não é exatamente o mesmo. Então assim, a gente tentou fazer um trabalho para que a gente chegasse a desenvolver um indicador, com um fator de correção que levasse em consideração a complexidade dos pacientes, do que a unidade atende, mas não conseguiu. (GC07).

Umas das coisas que a gente estava discutindo nesse período é a proposta de trazer para o conselho gestor dos hospitais representantes da comunidade, [...] é uma forma de cobrar mais de perto não só as metas, mas a qualidade do servico. (GCO9).

Outros órgãos que fazem publicização, são assessorados por nós na construção do projeto. Eles constroem o projeto com nossa metodologia. Já a Sesab não. [...] os relatórios que recebemos da Sesab não observa esse modelo. [...] O modelo de contrato de gestão da Sesab é bem atípico em relação aos outros contratos. [...] Ela tem uma estrutura própria que ela se divide em parte assistencial, parte jurídica etc. É por partes, então, cada equipe cuida de uma parte do contrato. [...] Eles criaram um processo, cada equipe cuida de uma parte do contrato. Então se você perguntar sobre o contrato sobre uma matéria que não é daquela equipe, ela não sabe Ihe dizer, eles fizeram a estrutura dessa forma. [...] O monitoramento é fragmentado, no processo de trabalho. [...] Os relatórios da Sesab só abordam a questão de indicadores de produção, de internação, de SADT. É com um ou dois blocos e alguns indicadores qualitativos. Ele não traz o contrato como um todo, como nosso padrão de relatório aborda, não é. É fragmentado. (GC10). 
Essas evidencias possibilitaram reconhecer que a instrumentalização contratual e dos relatórios de gestão são elementos de fragilidade na publicização da gestão hospitalar do SUS Bahia. Considerando os elementos do referencial teórico utilizado para analisar a capacidade gestora, cabe ressaltar a importância da categoria PCD, que constitui um dos vértices do $\mathrm{TFM}^{23}$ e que, no caso analisado, foi considerada como o aspecto mais fraco da gestão hospitalar.

\section{Considerações finais}

A primeira dimensão analítica tratou sobre o sistema de monitoramento e avaliação da gestão hospitalar, devendo destacar que os contratos de gestão são instrumentos frágeis e de pouco aprofundamento nos aspectos de acompanhamento e vigilância em relação ao cumprimento das ações contratadas pela SES. Inclusive, os participantes reiteraram essa crítica, considerando a fragmentação do método adotado pela Sesab e os problemas relatados que prejudicam a qualidade da avaliação.

Os instrumentos não apontam critérios de acompanhamento da melhoria das necessidades de saúde e condição sociossanitária, determinantes que devem pautar as ações implementadas pelos hospitais com vistas ao perfil epidemiológico da macrorregião. Também não são estabelecidos critérios avaliativos e de monitoramento sobre os desempenhos referidos pelas OS.

No que tange à preocupação com o desempenho, a análise dos contratos leva a acreditar que o Poder Executivo Estadual é contratante que assume a responsabilidade pela gestão eficiente e resolutiva, sendo que este deveria se ocupar da função regulatória, monitorando e fiscalizando a eficiência da organização que realiza a gestão. De fato, ele se compromete em subsidiar a OS contratada com valores estabelecidos, garantir acréscimos por aditivos/reembolso para alcance de prestação de serviços e permitir flexibilização de entraves burocráticos. Outrossim, cabe à contratada: respeito aos direitos trabalhistas, normas e princípios do SUS, comprovação da capacidade de desempenho, qualidade do serviço prestado e lançamento de dados nos Sistemas de Informação em Saúde. Todavia, percebe-se que a função regulatória do Estado não se desenvolveu rapidamente, exigindo esforços à melhoria do sistema de acompanhamento e controle.

Quanto ao cumprimento do plano contratualizado, destaca-se que, para além da heterogeneidade em relação ao porte hospitalar, a complexidade da gestão contratualizada por publicização é condicionada à baixa capacidade de monitoramento do nível central da atenção hospitalar. Houve readequação da parte variável conforme desempenho de $10 \%$ para $30 \%$ do orçamento total, tornando-se parte importante da composição financeira do instrumento contratual e estrategicamente estimulando a melhoria dos resultados. Outros condicionantes implicaram a fragilidade do monitoramento: dificuldades operacionais para visitas trimestrais, baixa capacidade da equipe de acompanhamento quanto aos aspectos jurídicos, contábil, trabalhista e predial. A fragilidade evidenciada aponta para a baixa implementação desse elemento regulador da publicização, que é marcante no âmbito estatal.

Deve-se destacar a responsabilidade estatal sobre a manutenção da oferta de serviços públicos com alternativa da gestão indireta. No instrumento contratual, o Estado transfere a competência de gestão do serviço, mas se mantém corresponsável pela prestação de serviços, apontando adoção de protocolos terapêuticos, valorizando certificação por acreditação e recomendando atuação de comissões com fomento de temas alinhados a implementação de políticas públicas sociais e de saúde. Da mesma forma, compromete-se a retomar a condução da gestão direta em casos de não cumprimento contratual da OS. 
Por fim, deve-se destacar que RHS é uma das centralidades analíticas nesses instrumentos de gestão. Primeiro porque corresponde a maior parte do orçamento destinado contratualmente; porém, não teve correlação com o valor acrescido nas publicizações dos hospitais da rede própria do SUS Bahia.

Assim, pode-se considerar que os instrumentos de contratualização e regulação somente serão estratégias fortes à regulação da publicização quando suas fragilidades forem superadas, de modo a permitir que o Estado regulador exerça sua atribuição de monitoramento fidedigno e contínuo, análise crítica consistente aos desempenhos dos parceiros contratados e superação dos entraves que condicionam a regulação sistêmica e, consequentemente, a qualidade do cuidado que é prestado à população.

\section{Colaboradores}

Santos TBS, Souza JS, Martins JS, Rosado LB e Pinto ICM contribuíram para concepção, planejamento, análise e interpretação de dados; elaboração do rascunho e revisão crítica do conteúdo; e aprovação da versão final do manuscrito.

\section{Referências}

1. Escorel S, Teixeira L. História da política de saúde no Brasil de 1822 a 1963. In: Giovanella L, organizadora. Políticas e sistema de saúde no Brasil. Rio de Janeiro: Fiocruz; 2012. p. 279-322.

2. Santos IS, Ugá MAD, Porto SM. O mix público-privado no Sistema de Saúde Brasileiro: financiamento, oferta e utilização de serviços de saúde. Ciênc Saúde Colet. 2008; 13(5):1431-1440.

3. Pinto ICM, Teixeira CF, Solla JJSP, et al. Organização do SUS e diferentes modalidades de gestão e gerenciamento dos serviços e recursos públicos de saúde. In: Paim JS, Almeida Filho N, organizadores. Saúde coletiva: teoria e prática. Rio de Janeiro: Medbook; 2014. p. 231-244.

4. Brasil. Presidência da República. Plano Diretor da Reforma do Aparelho do Estado. Brasília, DF: [s. n.]; 1995. 68 p. [acesso em 2018 out 13]. Disponível em: http://www.bresserpereira.org.br/Documents/ MARE/PlanoDiretor/planodiretor.pdf.

5. Brasil. Lei no 11.079, de 30 de dezembro de 2004 . Institui normas gerais para licitação e contratação de parceria público-privada no âmbito da administração pública. Diário Oficial da União. 31 Dez 2004.

6. Brasil. Ministério da Saúde. Portaria no 3.410, de 30 de dezembro de 2013. Estabelece as diretrizes para a contratualização de hospitais no âmbito do Sistema Único de Saúde (SUS) em consonância com a Política Nacional de Atenção Hospitalar (PNHOSP). Diário Oficial da União. 31 Dez 2013.

7. Brasil. Lei no 13.019, de 31 de julho de 2014. Estabelece o regime jurídico das parcerias voluntárias, envolvendo ou não transferências de recursos fi- 
nanceiros, entre a administração pública e as organizações da sociedade civil, em regime de mútua cooperação, para a consecução de finalidades de interesse público; define diretrizes para a política de fomento e de colaboração com organizações da sociedade civil; institui o termo de colaboração e o termo de fomento; e altera as Leis $\mathrm{n}^{\circ} \mathrm{s} 8.429$, de 2 de junho de 1992, e 9.790, de 23 de março de 1999. Diário Oficial da União. 1 Ago 2014.

8. Abrucio FL, Loureiro MR, organizadores. O Estado numa era de reformas: os anos FHC: Parte 2. Brasília, DF: Ministério do Planejamento; 2002.

9. Brasil. Ministério da Saúde. Portaria no 95, de 26 de janeiro de 2001. Norma Operacional da Assistência à Saúde / SUS - NOAS 01/2002. Diário Oficial da União. 27 Jan 2002.

10. Brasil. Ministério da Saúde. Portaria no 373, de 27 de janeiro de 2002. Norma Operacional da Assistência à Saúde. Diário Oficial da União. 28 Jan 2002.

11. Brasil. Ministério da Saúde. Portaria no 399, de 22 de fevereiro de 2006. Divulga o Pacto pela Saúde 2006 - Consolidação do SUS e aprova as Diretrizes Operacionais do Referido Pacto. Diário Oficial da União. 23 Fev 2006.

12. Brasil. Decreto no 7508, de 28 de junho de 2011. Regulamenta a Lei no 8080, de 19 de setembro de 1990, para dispor sobre a organização do Sistema Único de Saúde - SUS, o planejamento da saúde, a assistência à saúde e a articulação interfederativa, e dá outras providências. Diário Oficial da União. 29 Jun 2011.

13. Martins RM. Contratos Administrativos. Rev Eletrôn Direito Estado [internet]. 2009 jan-mar [acesso em 2018 abr 15]; (17):1-48. Disponível em: http:// www.direitodoestado.com.br.

14. Brasil. Ministério da Saúde. Portaria no 3.390, de 30 de dezembro de 2013. Institui a Política Nacional de Atenção Hospitalar (PNHOSP) no âmbito do Sistema Único de Saúde (SUS), estabelecendo se as diretrizes para a organização do componente hospi- talar da Rede de Atenção à Saúde. Diário Oficial da União. 31 Dez 2015.

15. Cenci AR, Bedin GL, Fisher RS. Do Liberalismo Ao Intervencionismo: $\mathrm{O}$ Estado como protagonista da (Des) Regulação. Rev Acad Bras Direito Const. 2011 jan-jun; (4):77-97.

16. Soares PF. Do Estado Liberal ao Estado Regulador: aspectos político-jurídicos. Conteúdo Jurídico [internet]. 2013 jun 28 [acesso em 2017 mar 15]. Disponível em: http://www.conteudojuridico.com. br/?artigos\&ver $=2.44127 \&$ seo $=1$.

17. Brasil. Ministério da Saúde. Portaria no 1559, de 10 de agosto de 2008. Institui a política Nacional de Regulação do Sistema Único de Saúde - SUS. Diário Oficial da União. 2 Ago 2008.

18. Vilarins GCM, Shimizu HE, Gutierrez MMU. A regulação em saúde: aspectos conceituais e operacionais. Saúde debate [internet]. 2012 out-dez [acesso em 2018 abr 15]; 36(95):640-647. Disponível em: http://www.scielo.br/scielo.php?script=sci arttext\&pid=S0103-11042012000400016\&lng=pt\& $\mathrm{nrm}=\mathrm{iso} \& \ln \mathrm{g}=\mathrm{e}$.

19. Coutinho NN. As organizações sociais e o contrato de gestão. Rev Dir Público [internet]. 2006 maio-ago [acesso em 2018 abr 15]; 1(2):25-40. Disponível em: http://www.uel.br/revistas/uel/index.php/ direitopub/article/viewFile/11565/10260.

20. Minayo MCS. O Desafio do Conhecimento: pesquisa qualitativa em saúde. 13. ed. São Paulo: Hucitec; 2013.

21. Bahia. Secretaria da Saúde do Estado. Plano Estadual de Saúde do Estado da Bahia (PES) 2007-2010. Rev Baiana Saúde Pública [internet]. 2009 [acesso em 2018 abr 15]; 33(supl.1):13-87. Disponível em: http://www.saude.ba.gov.br/pdf/PES - RBSP_ Vol33_Suplementol_2009.pdf.

22. Bahia. Secretaria da Saúde do Estado. Plano Estadual de Saúde 2012-2015. Rev Baiana Saúde Pública [internet]. 2012 [acesso em 2018 abr 15]; 
36(supl):1-66. Disponível em: http://files.bvs.br/ upload/S/0100-0233/2012/v36nSupl_1/a3491.pdf.

23. Matus C. Los cinturones Del gobierno. Caracas: Fondo Editorial Altadir; 1997.

24. Pinto ICM. Mudanças nas políticas públicas: a perspectiva do ciclo de política. Rev Políticas Públicas [internet]. 2008 jan-jun [acesso em 2018 abr 15]; 12(1):27-36. Disponível em: http://webcache.googleusercontent.com/ search?q=cache:GU_5jXv56hoJ:www.revistapoliticaspublicas.ufma.br/site/download.php?id_ publicacao $=153+\& \mathrm{~cd}=1 \& \mathrm{hl}=$ pt-BR\&ct $=$ clnk $\& g l=b r$.

25. Howlett M, Ramesh M, Perl A. Política pública. Seus ciclos e subsistemas: uma abordagem integradora. Rio de Janeiro: Elsevier; 2013.

26. Barbosa NB, Lima H, Trindade AMV, et al. As organizações sociais de saúde como forma de gestão público- privada em Goiás - o caso Huana. Rev Serv Público. 2015; 66(1):121-144.

27. Bonacim CAG, Araújo AMP. Influência do capital intelectual na avaliação de desempenho aplicada ao setor hospitalar. Ciênc Saúde Colet [internet]. 2010 [acesso em 2018 abr 15]; 15(supl.1):1249-1261. Disponível em: http://www. scielo.br/scielo.php?script=sci_arttext\&pid=S1413$-81232010000700034 \& \operatorname{lng}=$ pt\&tlng=pt.

28. Costa IG, Gofman B. As parcerias com as organizações sociais e a fiscalização por parte do Ministério público. Rev Aporia Jurídica. 2016 jun; (I):157-173.

29. Alcoforado F, Moraes TC. A Responsabilização na Gestão das Políticas Públicas a a Contratualização com Organizações Sociais. Rev Eletrôn Reforma Estado [internet]. 2008 nov [acesso em 2018 abr 15]; (15):1-14. Disponível em: http://www.direitodoesta- do.com.br/rere/edicao/15.

30. Barbosa AP, Malik AM. Desafios na organização de parcerias público-privadas em saúde no Brasil. Análise de projetos estruturados entre janeiro de 2010 e março de 2014. Rev Adm Pública [internet]. 2015 [acesso em 2018 abr 15]; 49(5):1143-1165. Disponível em: http://www.scielo.br/scielo.php?script=sci arttext\&pid=S0034-76122015000501143\&lng=pt\&tl ng=pt.

31. Sanches L, Pontes L, Barros C, et al., organizadores. Manual de Gestão: Programa Estadual de Organizações Sociais. 1. ed. Salvador: Secretaria de Administração do Estado; 2016.

32. Machado CV. Novos modelos de gerência nos hospitais públicos: as experiências recentes. Physis. 2001;11(1):105-197.

33. Barbosa NB, Elias PEM. As organizações sociais de saúde como forma de gestão público / privado. Ciênc Saúde Colet. 2010; 15(5):2483-2495.

34. Brasil. Ministério da Saúde. Portaria no 2.395, de 11 de outubro de 2011. Organiza o componente hospitalar da Rede de Atenção às Urgências do Sistema Único de Saúde (SUS). Diário Oficial da União. 12 Out 2011.

35. Ditterich RG, Moysés ST, Moysés SJ. O uso de contratos de gestão e incentivos profissionais no setor público de saúde. Cad Saúde Pública. 2012 abr; 28(4):615-627.

Recebido em 12/07/2017

Aprovado em 01/10/2018

Conflito de interesses: inexistente

Suporte financeiro: não houve 